\title{
Media and Democracy: a Plural Approach*
}

\author{
by Nelson Rosário de Souza \\ Universidade Federal do Paraná, Brazil
}

(Porto, Mauro P. Media Power and Democratization in Brazil: TV Globo and the Dilemmas of Political Accountability. New York/London: Routledge, 2012)

The central theme of Mauro Porto's analysis is the political role of the media in
contexts of democratic transition. His reflection is anchored in a case study of the Globo Television Network, a prominent nationwide network usually referred to as TV Globo. It is interesting to note that the history of theories on political communication runs jointly with the history of the rise of representative democracies. But lacunas still exist in the interface between communication and democracy, and the contributions of Porto's book are significant.

Power has been a topic of discussion ever since the first studies on the media were published. The model that opened up the debate, the "hypodermic theory," presented the thesis of the "unlimited effects" of the media over the behavior of individuals, the supposition being that the message acts on them directly and immediately (WOLF, 2005). The exaggeration of this initial analysis regarding the power of the media can be explained on the basis of its early theoretical and political context. The backdrop for the hypodermic theory was the emergence of behaviorism and mass psychology and the use of radio to mobilize the masses in totalitarian regimes, such as Nazism. Several later theories went beyond various drawbacks of the hypodermic theory, such as the fetishism of technique, discrimination toward "the masses," the supposition of the stupidity of audiences, the supposition of insulation, the fragility and passivity of the individuals who receive the messages, and even the fear of a democratization of culture (MAIGRET, 2010). Adorno and Horkheimer had insisted on the thesis of the unlimited power of the culture industry,

* http://dx.doi.org/10.1590/1981-38212014000100008 
but not as an attribute of the new communication technologies in themselves, but rather as an effect of the class struggle.

If today's theses about the power of conspiracy and manipulation of the media are not very appealing in intellectual circles, they are still held by some sectors of society. Porto raises questions about the relationships between the field of politics and the media in contexts of democratic transition. He notes the decline of the "instrumentalization" of the media in this process and gives priority to analyzing the accountability of the media toward the evolution of politics. The thesis of manipulation is clearly unable to explain the crossed influences among media institutions and politics in contexts of democratic transition. Interested in explaining the changes in media institutions involved in processes of opening up of politics, Porto examines the nuances of this relationship.

Criticisms of the hypodermic theory failed to get beyond the paradigm of "effects." It was not by chance that by overcoming initial views brought on the perspective that became known as "limited effects." The power of the media was relativized and even forgotten in favor of the attention given to its functionalistic view, as can be seen in the studies by Lazarsfeld (MAIGRET, 2010). The direction of concerns continued to mean the flow "from the influential media to the impressionable audience." The gradation of the effect of the media is what changed; it became less intense. Studies on the relationships between media and power continued to give priority to the verticality of the "effects," even though they were limited. This perspective, however, tells us very little about the horizontality of the relationships involving political institutions and their actors, and this is a central concern in Mauro Porto's work. This is very clear in his research questions: What do the specific configurations that involve the State, civil society and the mass media tell us about the quality of the representation and of the democracy in political contexts of transition? Is it possible to establish causality between changes in the relationship of the State to civil society, on the one hand, and transformations in political communication in new democracies, on the other? How do different configurations of the relations between State and civil society affect processes of political communication in new democracies?

The concept of agenda setting (McCOMBS \& SHAW, 1972) confirmed and sophisticated the paradigm known as "limited effects." This concept was partly inspired by Bernard Cohen's statement that the main success of the press is not to say how "people should think," but "what they should think about." The concept thus emphasizes the role of the press to line up topics, especially in electoral contexts. On the one hand, the concept of agenda setting minimizes the verticality embedded in the notion of "effects" because the media perceives the existence of an agenda of the public that is parallel to the media's agenda, and is not unaware of the disputes over the control of the agenda. This means that 
there is no guarantee of the effects of the media ${ }^{1}$. On the other hand, the vertical power of the media is restored when the concept of agenda setting is combined with the notions of framing and prominence or salience, since, in this case, the media is strong not only when setting agenda topics but also when proposing interpretative framing and determining positive and/or negative aspects in advance of the topics released to the audience. Maybe it is because the term "agenda setting" has this vertical meaning that Porto uses it with moderation. His main conceptual investment comes from the debate over representation and democracy.

It seems that theories on mass communication treated power but gave the greatest attention to its verticality, while theories on democracy ignored the mediated communication (MIGUEL, 2000). Therefore, the project Mauro Porto has taken on is not easy to carry out. None of the theoretical currents concerned with democracy give due value to the topic of communication. Those who study limited democracy, even when they defend freedom of opinion, place information in a back seat. There are several reasons for this: information does not protect voters from political manipulation; in their rationality, voters would see more costs than benefits in searching for information; political decisions depend on other factors and levels of willingness; individuals decide on the basis of their immediate experiences and perceptions, and are not susceptible to the mass media; lastly, the information market is self-regulating and, for this reason, there is no need for communication to be an object in political theory. These arguments are associated with the idea that political choices are essentially individual and circumscribed to the private sphere (MIGUEL, 2000).

As for the perspective of republican democracy, even though it exalts the public sphere, it also ignores the topic of communication. This may be because this perspective minimizes the factor of construction and conflict present in the formation of political preferences by presuming that the "general will," or the "overall well-being" are already given. But it may also be because republican democracy focuses more on direct participation and face-to-face communication on small scales, as the solution to problems generated by the mass media (MIGUEL, 2000). Neither does deliberative democracy try to theorize on the relationships between mass communication and politics. When this happens, analyses rise to high levels of abstraction and give great weight to ideal, or even utopian, conditions, about communication among free subjects who are objective, rational and searching for consensus. Even deliberative democrats who are in favor of debates as criteria for legitimating decisions rather than paths toward unanimity fail to face the "real" problem

1 In my understanding, the concept of "scenario of political representation" (CR-P) (LIMA, 2004) also contributes to a perception of the horizontal relationship between media, political institutions and the public. 
of mediated communication that is inescapable in mass democracies. These deliberative democrats minimize the central role of the media and give little importance to representation (MIGUEL, 2000).

This brief rundown tends in favor of Mauro Porto's book because the work stands out among the research works that are concerned with studying the proximity between media and politics, along with their institutions and actors. In other words, what is seen as important are contexts of democratization, in the sense that such contexts represent advances in the horizontal relationships between society and political institutions. The approach established by Porto compel him to search for analytic tools in the theory of democracy, namely, accountability and representation. In this direction Porto takes major steps in approximating the theoretical fields of the media and of democracy, proving that this conceptual interaction is strategic for clearer understanding of essential aspects of contemporary political reality. Porto holds that there can be no democratic politics without disputes over representation, in a broad sense, including both electoral delegation and cultural practices as seen by the author. The struggle for representation is also a conflict for the construction of reality and for discursive hegemony. In mass societies, therefore, this involves the field of mediated communication. This means that in the hypothesis launched by Porto, which holds that representation and accountability practices go along a line that connects State, civil society and mass media, may or may not generate crossed increments. This hypothesis is not only pertinent, it is also strategic. The interaction between these agents must be examined in order to explain the quality of the democracy. But it is also necessary in order to measure the accountability of the media, which is more important and more original in contexts of democratic transition. The media can both participate in the improvement of political representation and sustain positive discomforts from this process. In this case, says Porto, the main explanatory variable is the type of political context that emerges from the transition.

The perspective adopted in Porto's book is also different from the position presented by Manin, with his concept of "public democracy" (MANIN, 1995). According to Porto, even though this concept has the merit of opposing the pessimistic exaggeration regarding the role of the media in contemporary democracy, it fails by not perceiving the possibility of resistance of the actors in civil society (PORTO, 2012).

Porto launches the hypothesis that the media, and especially TV Globo, are not immune to transformations in the political sphere. The recent history of representative democracy in Brazil, marked by the transition from a more restrictive (authoritarian) model to a more inclusive one, resounds in TV Globo, the country's most influential media institution. To verify this hypothesis Porto organizes an analysis of the performance of TV Globo during the entire process of transition, divided into the following aspects: 1. 
Election coverage; 2. Presidential communications; and 3. Symbolic representation model in its soap operas. The conceptual references, therefore, present a double dimension. On the one hand they are guided by the debate on democracy; more precisely, they stress the importance of the concepts of representation and accountability. On the other hand, the references are anchored in the discussion on the meaning of symbolic representation proposed by the media. The construction of the object on the basis of this double entrance is innovative and contributes to the advance of inter-disciplinary approaches (MAIGRET, 2004; MATTELART \& NEVEU, 2004) that can do justice to both political and socio-cultural phenomena, simultaneously. It is essential to look at practices of the media without dwelling too much on economic determinism. But one should not underrate the exercise of power in this field (GRANJON \& PARIS, 2009).

The corpus of data sustaining that TV Globo was responsive to stimuli coming from civil society and from political institutions is very broad, as it includes interviews, electoral coverage, communication related to the Brazilian president's office, practices of media accountability, and the symbolic representation embedded in the soap operas. The author analyzes the behavior of the network in electoral and non-electoral situations, with his study going back to the 1960s to recount the history of TV Globo and the more specific history of the soap operas. The book also analyzes the journalistic coverage of five presidential elections, from 1989 to 2006.

To attain his objectives Porto divides the book into two parts. The first, containing two chapters, consists of a discussion on the theories of democratization and representation, giving special attention to the case of Latin America and the evolution of the media and the policies of accountability in contexts of recent democracy. The second part, divided into five chapters, consists of an analysis of the broad corpus of data available

In the first chapter the author discusses theoretical literature on democracy and democratic transition in Latin America. In the process he rejects the minimalist theory, because it emphasizes procedural and institutional aspects, and the ruling classes, in detriment to the role of civic groups. The theories that incorporate civil society and cultural factors offer more resources to the study of political practices of social actors, even though, warns Porto, these theories have not overcome the dichotomy between the elite and the masses; in other words, they lack a vertical glance. With backing from the comprehensive theory of political representation the author seeks to understand the nuances, asking about the role of the media in the quality of the democracy in given contexts and the effects of democracy on communications media. His answer calls for observation of the mediations between political institutions and civil society with the use of two conceptual tools: representation and accountability. Porto says that the media can play a fundamental role in improving the quality of democracy if it strengthens society's mechanisms of 
representation and accountability. This realization leads the author to include the media in the model of representative democracy, next to representative institutions, the public sphere, and associative networks. In this way, Porto seeks to fill in the gap he finds in democracy, specifically, the role of the media in democratic regimes. But he also seeks to give more consistency to analyses of the role of civil society in democratic contexts. According to him, even the point of view of political culture shows shortcomings in two aspects: it fails to coherently indicate the link between civic involvement and social capital, and it fails to gradate the impact of different types of associations on the process of democratization, and this leads to a romantization of the role of voluntary associations.

It seems obvious that media systems undergo changes with democratization. The tendency, in these cases, is a decline in instrumentalization and explicit biases. But Porto goes a step further by presenting an explanation as to how the new levels of mediation, beyond the electoral level, operate in the evolution of political contexts. The specific character of the relationships between political society, civil society and media are seen to be the primary factor to explain the generation of inclusive or restrictive representative democracies, and this justifies the attention Porto dedicates to social movements that attempt to make the media become more accountable.

Based on Porto's reflections it is plausible to consider that the virtuous circle of representative democracy could combine social mobilization with inclusive political institutions, thus strengthening political representation. For this reason, observation of the quality of representation is part and parcel of the analyses of democracy. To what extent do citizens have accountable representatives? Porto's question shows up the need to verify the degree of social control over institutions, including the media, in contexts of democratic transition. To this purpose, Porto adopts a sophisticated conception of representation that goes beyond represented interests and includes the dimensions of opinion and perspective. But the analysis would be broader, especially in terms of symbolic representation, if it also incorporated the dimension of the struggle for recognition, on the basis on the appropriation that feminist studies make of the concept of public sphere (FRASER, 2001). In any case, Porto makes an important contribution by incorporating symbolic representation conveyed by the media, as an essential element of communication that operates in the connection between State and civil society.

In the second chapter, Porto advances on the theoretical model that helps his readers understand how the media affects the machinery of political representation. His attention is focused on the type of connection that is established between the transformations in media institutions and the quality of the mechanisms of political accountability. Porto calls this focus the "political context of media transformation." The relationship between control by civil society and accountability of the authorities constitutes an important 
criterion for the quality of democracy. The author suggests that the media be included in this equation as part of the sphere of vertical political accountability, in the same way that symbolic representation is included. This perspective enables readers to wonder about the connections between transformations in the media and mechanisms of rendering accounts in contexts of democratic transition. The enterprise he proposes includes both efforts by the media as an agency of investigation and control, on the one hand and, on the other, the role played by citizens jointly pressuring the State and the media itself in processes of social accountability.

Porto holds that symbolic representation is essential for the quality of democracy because it denotes and supports persons and groups, occupying a central place in the struggle for the assertion of identities and legitimation of experiences. Symbolic representation makes it possible to judge whether interests, opinions and perspectives are finding channels for expression and how they change over time. This dimension also informs about the accountability to political pluralism by the system of representation. As stated above, the media plays a major role in this process by publicizing voices and legitimating actors and their demands. Finally, it strengthens representation, but can also raise barriers of invisibility and stereotypes. The perception of the strategic character of the symbolic dimension in the game of democracy is undoubtedly important in order to understand the connection between media and politics. However, I feel that Porto's perspective could be enhanced if he dialogued with the more recent heirs of Cultural Studies. Examples of this include David Morley in Great Britain and the "media culture" group in France, led by Eric Macé, Eric Maigret and Hervé Glevarec. The approximation would be promising because these authors also stress the importance of subjects' capacity to resist, and increase the concept of "public sphere," and making its boundaries less rigid. They also observe both hegemonic and counter-hegemonic procedures in the connections between media and politics.

The composition of Porto's theoretical framework is completed when he draws up a model that seeks to deal with the differences in Latin America regarding the democratic transition and outlines of the media system. He presents two realities without ignoring their possible variations. In the first he includes the countries where an inclusive representative democracy emerged, characterized by the strength of the political institutions, of civil society, of connections between the State and civil society, and of the movements of accountability over the media. In these cases, a virtuous circle can be seen marked by a strengthening of the politics of representation and by an open media system characterized as more balanced, through electoral coverage, more independence from the presidency and more plural representation of citizens. All this results in better performance in the area of social and vertical accountabilities and greater diversity in symbolic representation. A very different situation can be seen in countries marked by limited representative 
democracy. There, a vicious circle of inadequate political representation can be seen, with the media system less open and showing less independence, plurality, accountability and diversity in symbolic representation. The analysis of the data in the subsequent chapters of the book applies the model to the Brazilian situation, more precisely, to TV Globo. Porto's objective is to confirm the hypothesis of a connection between political institutions, civil society and the media. This means that the situation of inclusive democracy forces the media to remain open and, in this way, the media itself then operates positively regarding the democratic game.

The empirical analysis begins in Chapter Three, which opens the second part of the book, where the history of TV Globo is recounted. The author emphasizes the network's history, which began its rise in importance and influence (1965-1985) during the period of military dictatorship. He characterizes it as a closed and politically instrumentalized media institution. The context of democratic transition (1985-1995) represented no change in the network's postures, as it resisted the construction of an open media system. Porto divides the transformation of TV Globo into two phases, the first being between 1995 and 2001, and the second having begun in 2001 and continues till the present day. In this first characterization of the changes undergone by the network, the author discusses several explanatory factors. One of these factors was political orientation, and another had to do with undertakings were carried out by the network's owners, and the profile of the media market and the configuration of policies of the media. In the next chapters Porto further discusses the causes and consequences of the progressive opening of TV Globo, characterized by a more independent, assertive and plural model of journalism and by soap operas that progressively represented Brazilian identity in more a diversified way.

A great deal of information about the coverage of five presidential elections (1989, 1994, 1998, 2002 and 2006) by TV Globo sustains the thesis of Chapter Four, according to which Globo went through a process of opening up that contributed to improvements in the quality of political accountability and representation. During the period of election coverage, Globo's prime-time daily news program (Jornal Nacional) became less and less explicitly manipulative of the news and gradually allotted more evenly the time allotted to the main candidates. TV Globo set up coverage that became less and less unequal and biased toward one or another party. This stance, concerned with more balanced and pluralistic coverage contributed to the formation of more efficient deliberative space. But the setback of 2006 showed that this course was not linear and without its shortcomings. Emphasis on accusations rather than on topics of interest of the voters, for example, hampers evaluations by voters of the government's responses to the public.

One can always object that, due to its characteristics, electoral coverage is not the best criterion to judge whether a degree of openness has been attained by a television 
network. Consequently, Chapter Five analyzes the quality of TV Globo's coverage outside electoral periods, with the purpose of evaluating the performance of the network in terms of the management of communication from the top federal voices in Brasilia. In this chapter Porto analyzes six terms of office of five different presidents in sequence, between 1985 and 2006, the basic question being the dispute between the federal administration and the media about control over the news agenda. The expectation is to contribute to drawing up an analytic model that can apprehend the relationships between the management of news by the federal administration and the power of the media in new democracies. Without exhausting the valuable analysis in a few lines, it can be said that during the period when the network was closed against any independent or democratic positions, the presidents had more success in their strategies to control the news agenda, and the owner of TV Globo had greater influence over government authorities. The opening of the network, in turn, brought about changes in the communication strategies of the authorities, who became more professional, even though President Luís Inácio (Lula) adopted a personal stance for communicating directly with the population. In any case, Porto's position is that by adopting a more assertive and independent style of journalism, TV Globo refined its mechanisms of accountability and contributed to the limitation of presidential power.

The sixth chapter proposes the thesis of the opening up of TV Globo in terms of independence from the government, and notes the symbolic representation carried out by the network in its soap operas, especially in terms of Brazilian national identity. Porto is precise in his attention to the contradictions and tensions involving the construction of a "Brazilian national identity," seeking support in the tradition of Cultural Studies and in the concept of mediation. He therefore correctly disqualifies the idea of culture as a reflection of something. Cultural space is more an environment for negotiating meanings and disputes, basically, of mediation. The author refers to a wide variety of soap operas broadcast during the period extending from the military dictatorship to redemocratization. Due to Brazilian cultural characteristics, this genre is seen by the author as significant public space for the emergence and negotiation of images related to Brazilian national identity and its social problems. Porto explores the connections between the soap operas, their themes and their approaches, on the one hand, and the different historical contexts present between 1965 and 2006, on the other. The genre varied its themes, going from nationalism based on middle class opinions and values, and concretized by the market, to the incorporation of new cultural values generated by the growing mobilization of civil society in the 1980s and 1990s. The soap operas offered space to new themes associated with the new vector, from bottom to top and from the social to the political. Faithful to his optimistic point of view, Mauro Porto holds that despite many stereotyped representations, the greater visibility of marginal viewpoints in the soap operas means advances 
for these groups in the disputes in representative democracy. In both analytic and political terms, it would be important to get beyond visibility as a criterion for evaluating the media in conflicts of identities. The concept of acculturation, understood as the media's ability to incorporate and resignify critical discourses and currents of resistance, has the potential to apprehend the nuances of this game beyond visibility (SOUZA, 2013). It is also important to note that resource to studies on reception could strengthen the analyses of this chapter.

The last chapter of the book is dedicated to an analysis of the most recent forms of mobilization of civil society with the objective of making the media more open to its demands. Porto classifies these movements under the label he calls "media accountability movements (MAMs)," a category that includes phenomena ranging from systems of monitoring to forums, and including protest movements. MAMs, sometimes allied with the government, play an important role in bringing about change in media organizations, as well as other factors treated in the book. Porto correctly perceives the diversity of civil organizations occupied in pressuring communication companies, and analyzes the inconsistencies in their criteria for evaluating the media's performance, since such groups reflect social positions and the interests of social classes.

To summarize, the analysis of data presented in the book indicates that TV Globo underwent broad changes and that it is pertinent to associate these changes with the evolution that took place in Brazilian representative democracy. In the restrictive context there was government control over the agenda and interference by the owners of the network, combined with journalism that displayed explicit biases, together with very minimal accountability by both government and the media. The inclusive environment favored a number of factors, including more balanced journalistic coverage, the presence of social organizations of control over the media, more plural symbolic representation of national identity and, therefore, greater accountability of both government and media. In contexts of inclusion the media runs risks if it maintains the old politics of alliances, a factor that led TV Globo along a pathway toward journalistic openness by assuming greater independence and taking plural approaches. Soap operas also went through an evolution to a situation where diversity was incorporated into the representation of Brazilian national identity, but with more pluralism and diversity.

Porto clearly makes an important contribution for developing a model of the political context of the transformation of the media. His analysis opens up valuable possibilities for comparative studies, for example, among Brazil, Venezuela and Argentina, nations that have recently gone through complex historical processes of democratization associated with specific forms of organization in the relationships between political institutions, civil society and the media. 
The book is important both for the broad contents treated in depth and for its plural approach. One especially important aspect is that the book points out the need for future studies that will incorporate discussions on the politics of identity in analyses of the role of the media in the democratic game. We must go beyond the perception of new representations of identities in the media and discuss their political meanings on the basis of a broadened conception of power.

Looking at Brazilian television and, more specifically, at TV Globo in a historical perspective favors optimism. A short-term perspective might have expected explanations from Porto about the scarcity of debates, the lack of plurality in TV Globo's journalism and even its practice of disqualifying politics as a whole. But these questions are outside the scope of his book.

\section{References}

FRASER, Nancy (2001), Repensando la esfera pública: una contribución à la critica de la democracia actualmente existente. Available at http://www.equidad.scjn.gob.mx/IMG/ pdf/REPENSANDO_LA_ESFERA_PUBLICA.pdf

GRANJON, Fabien and PARIS, Emmanuel (2009), A critical approach to French média cultures theory: Post-critical sociology of media and cultural studies in France. Global Media and Communication, Vol. 5, No. 3, pp. 279-294. Available at http://gmc.sagepub.com/ content/5/3/279. Access in 17/4/2013.

LIMA, Venício (2004), Cenários de Representação da Política. In: RUBIM , A. \& AZEVEDO, F. (Org.) Comunicação Política: Conceitos e Abordagens. Salvador: Edufba, pp. 9-40.

MAIGRET, Éric (2004), Sociologie et Communication: vieilles lunes disciplinaires et idées neuves. Hermès, № 38, pp. 111-117.

MAIGRET, Éric (2010), Sociologia da comunicação e das mídias. São Paulo: Editora Senac.

MANIN, Bernard (1995), As metamorfoses do governo representativo. Revista Brasileira de Ciências Sociais, Vol 10, No 29, 10, pp. 5-34. São Paulo: Anpocs. Available at http://www. anpocs.org.br/portal/publicacoes/rbcs_00_29/rbcs29_01.htm

MATTELART, Armand and NEVEU, Érik (2004), Introdução aos estudos culturais. São Paulo: Parábola.

McCOMBS, Maxwell E. and SHAW, Donald L. (1972), The Agenda-Setting Function of Mass Media. Public Opinion Quarterly, № 36 (Summer), pp. 176-187.

MIGUEL, Luis F. (2000), Um ponto cego nas teorias da democracia: os meios de comunicação. BIB - Revista de Informação Bibliográfica em Ciências Sociais, № 49, pp. 41-79.

PORTO, Mauro P. (2012), Media Power and Democratization in Brazil: TV Globo and the Dilemmas of Political Accountability. New York/London: Routledge. 
SOUZA, Nelson R. (2013), Poder e consumo midiático: tensões entre os olhares micro e macrossocial no espaço público contemporâneo. $37^{\circ}$ Anpocs Meeting in Águas de Lindóia. Available at file://C:/Users/Nelson/Downloads/NelsonSouza\%20(2).pdf

WOLF, Mauro (2005), Teorias das comunicações de massa. São Paulo: Martins Fontes. 